\title{
Maternal and neonatal service usage and determinants in fragile and conflict-affected situations: a systematic review of Asia and the Middle-East
}

Saji S. Gopalan ${ }^{1 *}$, Ashis Das ${ }^{2}$ and Natasha Howard ${ }^{1}$

\begin{abstract}
Background: Fragile and conflict-affected situations (FCS) in Asia and the Middle-East contribute significantly to global maternal and neonatal deaths. This systematic review explored maternal and neonatal health (MNH) services usage and determinants in FCS in Asia and the Middle-East to inform policy on health service provision in these challenging settings.

Methods: This systematic review was conducted using a standardised protocol. Pubmed, Embase, Web of Science, and selected development agency websites were searched for studies meeting inclusion criteria. Studies were assessed for methodological quality using an adapted evaluation tool. Qualitative and quantitative data were synthesized and pooled odds ratios generated for meta-analysis of service-usage determinants.

Results: Of 18 eligible peer-reviewed studies, eight were from Nepal, four from Afghanistan, and two each from Iraq, Yemen, and the Palestinian Territories. Fragile situations provide limited evidence on emergency obstetric care, postnatal care, and newborn services. Usage of MNH services was low in all FCS, irrespective of economic growth level. Demand-side determinants of service-usage were transportation, female education, autonomy, health awareness, and ability-to-pay. Supply-side determinants included service availability and quality, existence of community health-workers, costs, and informal payments in health facilities. Evidence is particularly sparse on $\mathrm{MNH}$ in acute crises, and remains limited in fragile situations generally.

Conclusions: Findings emphasize that poor MNH status in FCS is a leading contributor to the burden of maternal and neonatal ill-health in Asia and the Middle-East. Essential services for skilled birth attendance and emergency obstetric, newborn, and postnatal care require improvement in FCS. FCS require additional resources and policy attention to address the barriers to appropriate MNH care. Authors discuss the 'targeted policy approach for vulnerable groups' as a means of addressing MNH service usage inequities.
\end{abstract}

Keywords: Fragile and conflict-affected, Maternal and neonatal health, Care-seeking, Service usage, Asia, Middle-East

\footnotetext{
* Correspondence: Saji.Saraswathy-Gopalan@lshtm.ac.uk

'London School of Hygiene and Tropical Medicine (LSHTM), London, UK

Full list of author information is available at the end of the article
} 


\section{Background}

The United Nations' post-2015 agenda calls for specific attention to address maternal and neonatal health $(\mathrm{MNH})$ in fragile and conflict-affected situations (FCS). Evidence indicates that without improving $\mathrm{MNH}$ service quality and usage in FCS, maternal and child health indicators will not improve sufficiently to achieve Sustainable Development Goal targets [1]. To implement strategic MNH interventions, FCS lack basic information on usage of $\mathrm{MNH}$ services and factors affecting access to $\mathrm{MNH}$ care.

Globally, 1.2 billion people inhabit fragile countries, while 800 million live in situations of conflict [1]. FCS are defined variously by different agencies [1-3]. However, key criteria include government not delivering core social services, instable governance with weak institutionalization and accountability, low socioeconomic and humandevelopment indicators, and threats to security and right to life from routine internal and external conflicts. Fragility and conflict coexist in many countries (e.g. Afghanistan, Palestinian Territories) [2], while post-conflict categorisations (e.g. Nepal), can still include fragility due to weak governance and social services delivery [1-3]. Weak governance, violent political conflict and adverse living situations challenge necessary improvement of health and living standards in FCS, and gradually impede global economic momentum [3, 4].

Appropriate and equitable MNH service usage is prerequisite to reducing maternal and newborn ill-health, especially in FCS [5]. Evidence indicates that providing skilled birth attendance (SBA) and addressing complications during pregnancy is potential to reduce $13-33 \%$ of maternal deaths [6]. Similarly, up to two-thirds of newborn deaths are preventable with provision of essential newborn care at birth and during the first week of life [6]. FCS perform poorly on MNH as they lack the governance and infrastructural capacity to provide SBA, emergency obstetric and newborn care (EmONC), contraception, and address related maternal and neonatal complications [5].

Although poor MNH status is a concern in FCS globally, FCS in Asia and the Middle-East are particularly relevant, with poor $\mathrm{MNH}$ indicators relegating several low- and middle-income FCS as some of the worst globally, e.g. Afghanistan and Yemen [7]. Several Asian countries did not achieve MDGs 4 and 5, due to fragility and conflict (e.g. Nepal, Afghanistan) [7-10]. The average maternal mortality ratio in this region is 200 deaths per 100,000 live births $[9,10]$. Long-term fragility is one key reason. For instance, Yemen, a chronically fragile country, has a higher maternal mortality ratio of 500/ 100,000 [9]. Among other top contributors of maternal deaths in this region, the Palestinian Territories and Iraq are prone to conflicts, whereas Nepal has been fragile for years [2]. Asian FCS have some of the highest rates of neonatal mortality globally. For example, Afghanistan, a conflict-affected country, accounts for $2 \%$ (i.e. 36,777 deaths) of global neonatal mortality [11-13].

FCS in Asia and the Middle-East require substantial informing evidence on $\mathrm{MNH}$ service usage and its determinants to help streamline policy strategizing, yet available information is limited [1]. As levels of fragility and conflict vary among FCS, so does their ability to deliver $\mathrm{MNH}$ services [7]. Further MNH investments in the FCS of this region are unlikely to be cost-effective without a greater understanding of MNH service usage and identification of demand-and supply-side challenges and opportunities.

\section{Objectives}

The aim of this systematic review was to identify and analyse the literature on maternal and neonatal serviceusage and potential determinants in FCS of Asia and the Middle-East. This region was selected because FCS here are leading contributors to the global maternal and neonatal morbidity burden and contribute relatively more eligible literature enabling a systematic review. Objectives were to (i) summarise the main findings on maternal and neonatal service-usage and (ii) identify key determinants of maternal and neonatal service usage. Implications for policy and practice were considered.

\section{Methods}

\section{Protocol and registration}

Using the criteria shown in Table 1, eight low- and middle-income FCS were selected (i.e. Afghanistan, Iraq, Myanmar, Nepal, the Palestinian Territories, Syria, Timor-Leste, Yemen). As FCS were defined through national scoring, no attempt was made to include additional countries with sub-national areas of fragility (e.g. India) that did not fulfil scoring criteria. A predesigned protocol guided the review processes, including search strategy, study selection, data extraction, quality assessment, and data synthesis. Reporting uses PRISMA (Preferred Reporting Items for Systematic Reviews and Meta-analyses) guidelines [13]. This review is registered with PROSPERO (International Prospective Register of Systematic Reviews) at the National Institute of Health Research, USA, as CRD42014014537 [14].

\section{Information sources and search}

The literature search was conducted in April 2014. First, authors searched electronic databases Embase, PubMed, and Web of Science systematically. Second, authors purposefully searched agency websites of Asian Development Bank, DFID, OECD, World Bank, and WHO. Third, authors identified potentially relevant citations from included studies and hand-searched them in relevant 
Table 1 Conceptual definitions

\begin{tabular}{ll}
\hline Concept & Definition \\
\hline Asia & The largest continent in the world, occupying the eastern part of the Eurasian landmass and its adjacent \\
& islands, and bordered by the Ural Mountains, Arctic, Pacific and Indian Oceans, and Mediterranean and \\
& Red Seas. \\
& Countries eligible for inclusion are those territorially part of the Asian continent without any inter-continental \\
& territorial disputes [48]. \\
& A term referring, generally, to the geographical area and countries between the Black Sea to the north and the \\
& Arabian Sea to the south, including Iran and Egypt (e.g. Egypt, Iraq, Iran, Israel/Palestine, Jordan, Kuwait, \\
Middle East & Lebanon, Oman, Qatar, Saudi Arabia, Syria, Turkey, United Arab Emirates, Yemen) [48]. \\
& The World Bank Harmonised List of Fragile Situations (FY14) was used, as it is accepted by several development \\
Fragile and conflict-affected & banks and agencies [49]. \\
situation (FCS & Criteria are either (a) a harmonized average country performance Indicator assessment (CPIA) rating of 3.2 or \\
& less, or (b) the presence of a UN and/or regional peace-keeping or peace-building mission during the past \\
& three years. \\
& CPIA consists of performance rating against 16 criteria in four clusters: (i) economic management, (ii) structural \\
& policies, (iii) policies for social inclusion/equity, and (iv) public-sector management and institutions [50]. \\
& Use of health services and supplies, it is commonly measured in terms of patterns or rates per unit of \\
& population at risk during a specified time-period [49, 51]. \\
& Any preventive and curative services related to pregnancy, childbirth and the postpartum period [51]. Services \\
include antenatal care, any delivery-related care (e.g. home delivery, institutional delivery, skilled attendance), \\
emergency obstetric care, and postpartum care [49, 51]. \\
Any preventive and curative postnatal services during the first 28 days after birth, including early breastfeeding \\
Maternices usage \\
within an hour of birth, exclusive breastfeeding, treating illnesses and symptoms, and newborn vaccination [49, 51].
\end{tabular}

journals identified. Search strategies and terms were adapted as appropriate for each database and site, with a combination of $\mathrm{MeSH}$ and non-MeSH terms using Boolean operators "AND" and "OR". Key search topics were:

$$
\begin{aligned}
& \text { "maternal health/care" [MeSH] OR "childbirth" } \\
& \text { [MeSH] OR "institutional delivery" OR "skilled birth } \\
& \text { attendance" OR "antenatal /prenatal" OR "postnatal/ } \\
& \text { postpartum" OR "neonatal/perinatal/newborn" OR } \\
& \text { "infant" OR "child care/health" or "under-five care/ } \\
& \text { health" AND "fragile setting/context" OR "crisis } \\
& \text { setting" OR "conflict-affected region/areas" OR } \\
& \text { "Afghanistan" OR "Nepal” OR "Myanmar/Burma" Or } \\
& \text { "Timor-Leste/East Timor" OR "Yemen" OR "West } \\
& \text { Bank and Gaza/Palestine/Palestinian Territories" OR } \\
& \text { "Iraq" OR "Syria" OR "Asia" OR "Middle-East" }
\end{aligned}
$$

\section{Eligibility criteria and study selection}

Inclusion and exclusion criteria were established through an iterative process. Authors agreed initial selection criteria based on the research question (i.e. "What are the status and determinants of maternal and neonatal health and service-usage in FCS of Asia and MiddleEast?"), focusing on primary research. Any primary study (i.e. peer-reviewed article reporting quantitative, qualitative and mixed-methods design) was considered if published in English during 2000-2013 and reporting maternal or neonatal service usage or determinants in Asian and Middle-Eastern FCS.

Policy evaluations, reviews and discussion papers were excluded. Studies given a low quality-score during methodological assessment were also excluded. The first author reviewed title, abstract and key words of all articles retrieved. Those articles meeting eligibility criteria were selected for full review. A second author checked selection of relevant abstracts and full articles. Any disagreements prompted another round of scrutiny until consensus was reached.

\section{Data collection}

Data were extracted from each record into an Excel spreadsheet. Headings included: lead author, co-authors, year of publication, type of source (e.g. PubMed, website), study setting, study design, outcomes of interest, number and type of participants, participant selection criteria, sample size, data analysis and reporting, limitations, and methodological quality score.

\section{Data items}

Study outcomes were restricted to service-usage for any of antenatal care (ANC), institutional delivery, skilled birth attendance (SBA), emergency obstetric and neonatal care (EmONC), postnatal care (PNC), early breastfeeding, newborn consultation for any perceived morbidity, and newborn vaccination. Any ANC was considered (e.g. any visit, all four visits, ANC from a skilled or unskilled provider). For PNC, any visit and PNC from a skilled or unskilled provider were considered. Factors affecting maternal and neonatal health services usages were included in the synthesis.

\section{Risk of bias in studies}

Authors adapted the McGill University Mixed-Methods Appraisal Tool (MMAT) [15], which has been used to 
assess methodological quality of both mixed-methods and primary cross-sectional studies (Table 2). In adapting this tool, authors excluded irrelevant indicators (e.g. are measurements appropriate?) and included new ones (e.g. was there any recall bias in reporting data?). Nine indicators were considered for both quantitative and qualitative studies, with each scored 1 if present and zero otherwise. Summative scores indicated overall study quality (e.g. six and above was considered high quality, 4-5 medium quality, less than four low quality and therefore excluded). For mixed-method studies, the maximum summative score was 12 (i.e. nine and above was high quality, 6-8 was medium quality, less than 6 was low-quality and therefore excluded). Two authors assessed quality independently, with disagreements resolved by discussion.

\section{Summary measures and data synthesis}

Summary measures were percentages and odds ratios (ORs) with a confidence interval of 90,95 or $99 \%$ significance. Based on the heterogeneity of data, a narrative synthesis was conducted, combining both qualitative and quantitative data. If feasible, quantitative data were subjected to meta-analysis using fixed effects with odds ratios pooled for similar determinants in particular services. Forest plots were generated for each determinant with odds ratios and confidence intervals displayed. Heterogeneity among studies was tested using I [1] statistics in Stata 13. Narrative synthesis was used for qualitative data on determinants of MNH service usage to describe and compare findings across settings, types of services and population groups.

\section{Results}

\section{Study selection}

Figure 1 details the stages of study selection. Initially, after removing duplicates 1319 records were identified as potentially relevant. After excluding irrelevant articles, 274 abstracts were screened, of which 36 were eligible for full text review. Finally, 18 peer-reviewed articles were selected for inclusion.

\section{Study characteristics and methodological quality}

Table 3 shows that among 18 studies included, eight (44\%) were from Nepal [16-23], four (22\%) from Afghanistan [24-27], and two (11\%) each from Iraq, Yemen, and the Palestinian Territories [28-33]. Fourteen (77\%) were quantitative studies (i.e. 11 cross-sectional surveys, 2 (11\%) used national health survey data, 1 prospective cohort study), two (11\%) were qualitative, and two (11\%) used mixed-methods designs. All studies included met the required methodological quality criteria suggested by MMAT (Table 2) particularly for data collection, analysis, and reporting. Twelve (66\%) studies received a high methodological quality score and 7 (38\%) received a medium score. Studies exhibited a few minor quality issues as described below.

None of the quantitative studies was nationally representative or generalisable. Data analysis was not presented with considerable details in Devkota and Bhatta [17], Khorrami et al. [25], Mayhew et al. [20] or Najem and Al-deen [28]. Khorrami et al. [25], Mayhew et al. [20], Najem and Al-deen [28], Sharma et al. [21] and Ulak et al. [23] did not provide sufficient details on study settings. Three studies (e.g. Devkota and Bhatta [17], Karkee et al. [19], Shrestha et al. [22]) focused on remote fragile settings. Dhaher et al. [32], by examining factors affecting postnatal care in Palestine, reflected the status of postpartum women in a conflict-affected setting. Among qualitative studies, Rahmani and Brekke [27] did not triangulate information from several data sources.

Neither mixed-methods study (i.e. Kempe et al. [31], Basaleem et al. [30]) was nationally representative and generalisability was not addressed. Kempe et al. [31], did

Table 2 Methodological quality assessment criteria adapted from MMAT

\begin{tabular}{ll}
\hline Assessment criteria & Indicators \\
\hline $\begin{array}{ll}\text { Scientific rigor of data collection, analysis and } \\
\text { reporting of qualitative studies }\end{array}$ & $\begin{array}{l}\text { Are the sources of qualitative data (i.e. informants, observations, documents) relevant to address the } \\
\text { research question? }\end{array}$ \\
& Is the process for analysing qualitative data relevant to address the research question? \\
& Is appropriate consideration given to how findings relate to the context (e.g. setting in which data \\
& were collected? \\
& $\begin{array}{l}\text { Is appropriate consideration given to how findings relate to researchers' influence (e.g. through their } \\
\text { interactions with participants)? }\end{array}$ \\
$\begin{array}{ll}\text { Scientific rigour of data collection, analysis and } \\
\text { reporting of quantitative studies }\end{array}$ & $\begin{array}{l}\text { Is the sampling strategy relevant to address the quantitative research question (quantitative aspect } \\
\text { of the mixed methods question)? }\end{array}$ \\
Is the sample representative of the population under study? & Is there an acceptable response rate (e.g. $60 \%$ or above)? \\
& Are the statistical methods used appropriate for measurement? \\
& Was there any recall bias in reporting data?
\end{tabular}




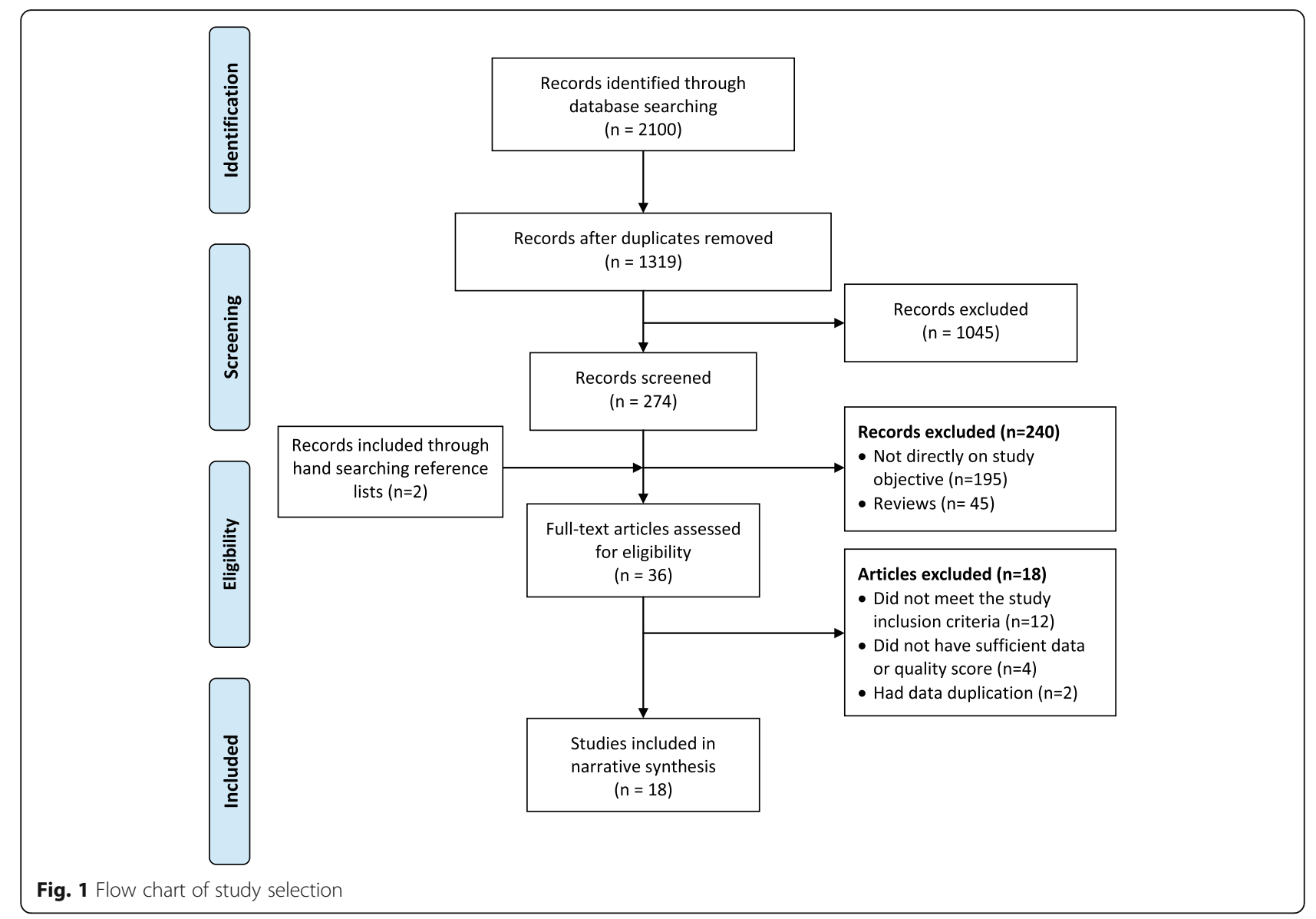

not give adequate description on the processes of data analysis or the necessity of using qualitative data. Basaleem et al. [30] used a mixed-methods design to explore maternal health and influence of women's autonomy in Yemen. In this study, details on study setting and quantitative data analysis were not clearly explained, while statistical analyses of determinants were not in-depth [31].

\section{Service-usage}

Table 4 provides service-usage findings. Three studies (17\%) described ANC usage [16, 17, 30]. Overall, at least one ANC visit was above $50 \%$ in both Nepal and Yemen $[16,17,30]$. More than $60 \%$ of Yemeni women obtained ANC from a professionally trained provider in the first trimester [16].

Five studies (27\%) mentioned SBA usage [16-18, 20, 31]. There was a sizable difference in SBA usage across studies from $13 \%$ in Nepal to $50 \%$ in Yemen [20, 30]. Kempe et al. [31] noted usage of untrained traditional birth attendants (32\%) was much higher than of medical doctors $(17 \%)$ or nurse-midwives (13\%) in Yemen. Three studies discussed institutional delivery $[17,19,33]$, which ranged from $85 \%$ in Nepal to 97\% in Palestine [19, 33]. Giacaman et al. [33] noted that usage was higher for government (56\%) compared to private (28\%) facilities for childbirth in the Palestinian Territories.

Three studies (17\%) discussed PNC, with less than 40\% coverage found in Palestine, Yemen and Nepal $[18,30,32]$. More than 70 and $60 \%$ of those sampled received PNC from hospitals and trained physicians respectively [18]. Two studies (11\%), from Nepal and Iraq, discussed newborn care $[17,23,28]$. Breastfeeding within an hour of delivery ranged from 7 to $57 \%$. In Nepal and Iraq studies, $70 \%$ of mothers did not seek any professional advice on newborn health and $30 \%$ did not vaccinate newborns $[16,28]$.

\section{Determinants of service usage}

Table 5 summarises findings on determinants of service usage. Determinants of SBA were discussed in three studies from Iraq and Nepal [16, 20, 29]. Women who depended on TBAs for delivery were generally less educated, less wealthy, and older [29]. Having at least four ANC visits, knowledge of pregnancy danger signs, residing near a facility, being wealthier and bettereducated were demand-side factors increasing the probability of SBA usage [16, 20, 29]. Pooled odds ratios (Fig. 2) showed education was associated with a $20 \%$ 
Table 3 Study characteristics and quality score, ordered by country and year

\begin{tabular}{|c|c|c|c|c|}
\hline Author (year) & Country & Design & Sample & Score \\
\hline Newbrander et al. (2013) [26] & Afghanistan & Qualitative & 30 IDIs and 29 FGDs with community members in 5 districts & $6 / 9$ \\
\hline Rahmani and Brekke (2013) [27] & Afghanistan & Qualitative & $\begin{array}{l}12 \text { IDIs with pregnant/recently-delivered women and } 15 \mathrm{IDIs} \text { with } \\
\text { providers in } 2 \text { provinces }\end{array}$ & $6 / 9$ \\
\hline Hirose et al. (2011) [24] & Afghanistan & Cross-sectional & 411 paired couples surveyed at 1 regional hospital & $7 / 9$ \\
\hline Mayhew et al. (2008) [20] & Afghanistan & Cross-sectional & 9917 recently-delivered (2 years) women surveyed in 33 provinces & $5 / 9$ \\
\hline Khorrami et al. (2008) [25] & Afghanistan & Cross-sectional & 292 women inpatients with obstetric complaints surveyed at 1 hospital & $5 / 9$ \\
\hline Najem and Al-Deen (2011) [28] & Iraq & Cross-sectional & 251 primipara postnatal mothers surveyed at 1 hospital & $4 / 9$ \\
\hline Siziya et al. (2009) [29] & Iraq & Secondary survey & 22,980 recently-delivered (1 year) MICS participants & $8 / 9$ \\
\hline Sharma et al. (2014) [21] & Nepal & Cross-sectional & 240 recently-delivered (1 year) women surveyed in 1 district. & $5 / 9$ \\
\hline Choulagai et al. (2013) [16] & Nepal & Cross-sectional & 2481 recently-delivered (1 year) women surveyed in 3 districts & $7 / 9$ \\
\hline Karkee et al. (2013) [19] & Nepal & Prospective cohort & 700 pregnant women in 1 district & $7 / 9$ \\
\hline Shrestha et al. (2012) [22] & Nepal & Cross-sectional & 732 married reproductive-age women & $6 / 9$ \\
\hline Ulak et al. (2012) [23] & Nepal & Cross-sectional & 352 mothers of infants attending vaccination & $6 / 9$ \\
\hline Devkota and Bhatta (2011) [17] & Nepal & Cross-sectional & 71 mothers of newborns & $4 / 9$ \\
\hline Dhakal et al. (2011) [18] & Nepal & Cross-sectional & 150 recently-delivered women & $7 / 9$ \\
\hline Dhaher et al. (2008) [32] & Palestine & Cross-sectional & 264 postpartum outpatient women & $7 / 9$ \\
\hline Giacaman et al. (2007) [33] & Palestine & DHS survey & 2158 women residing in the West Bank and Gaza Strip & $7 / 9$ \\
\hline Kempe et al. (2013) [31] & Yemen & Mixed-methods & 220 women with childbirth experience in urban/rural areas & $7 / 12$ \\
\hline Basaleem (2012) [30] & Yemen & Mixed-methods & 1678 women surveyed and 11 FGDs with men and women & $9 / 12$ \\
\hline
\end{tabular}

increased odds of SBA usage (OR 1.2, 95\% CI 1.07-1.33), whereas wealth quintile was not significant (OR 0.89, 95\% CI 0.74-1.04). On the supply-side, having more than one female traditional birth attendant (TBA) and community health-worker in the community, and at least one female doctor and provision of antenatal and emergency obstetric care in the facility increased SBA usage [20]. Similarly, absence of user fees and availability of health insurance increased the odds of SBA usage [20]. Qualitative studies indicated that women's autonomy over decision-making about her health and personal life was a decisive factor in using SBA [31]. However, despite having autonomy several nomadic women in Yemen reported not wanting SBA $[26,31]$. Two studies (11\%) indicated that informal payments restricted timely access to facility care among pregnant women [26, 31].

Determinants of facility-based delivery were discussed in five (27\%) studies [19, 21, 22, 29, 33]. Usage was higher among women with at least one ANC visit, more education, younger, employed, belonging to higherstatus social groups, and who resided near facilities and in physically-accessible areas [18, 19, 21, 22, 33]. Metaanalysis indicated education was a significant determinant across most studies. Pooled odds ratios showed education was significantly associated with a higher proportion of facility-based delivery (OR 2.78, 95\% CI 1.63-3.94). Qualitative research in Yemen indicated women preferred facility-based delivery given adequate staff, medicines, emergency care, cleanliness and arrangements for labour induction and neonatal resuscitation [30]. Public hospitals were reportedly preferred by Yemeni women due to the presence of qualified staff. [30] However, some women preferred home delivery for feelings of security, family support, and lower costs [30].

Determinants of delayed EmONC was discussed in two $(11 \%)$ studies $[24,25]$. These included not attending any ANC, care-seeking from traditional healers, and not wanting facility-based delivery. Absence of a midwife in the community or a facility also contributed to delayed EmONC. One study showed that residing near a facility, availability of an automobile for travel, inexpensive services, and perceived availability of safe care at the facility all increased the odds of EmONC usage [25].

\section{Discussion}

\section{Summary of evidence}

This systematic review synthesized the limited qualitative and quantitative evidence on maternal and neonatal service usage and its determinants in fragile and conflict-affected situations in Asia and the Middle-East. Relevant findings are similar to those in non-FCS, but more difficult to resolve given the unique challenges of FCS. These include disparities in the usage of essential $\mathrm{MNH}$ services among different socioeconomic, demographic and geographic groups even within FCS, with disadvantaged groups (e.g. women with no formal education, living at a distance from health facilities) facing additional barriers. This highlights the need to improve 
Table 4 Maternal and neonatal service usage, ordered by service type and \% usage

\begin{tabular}{|c|c|c|c|}
\hline Service & Study & Outcome & $\%$ usage \\
\hline \multirow[t]{4}{*}{ Antenatal care (ANC) } & Basaleem (2012) [30] & Professional ANC & $97.7 \%$ \\
\hline & & ANC in $1^{\text {st }}$ trimester & $60 \%$ \\
\hline & Choulagai et al. (2013) [16] & $4+\mathrm{ANC}$ & $57 \%$ \\
\hline & Devkota and Bhatta (2011) [17] & At least one ANC & $71.8 \%$ \\
\hline \multirow[t]{9}{*}{ Skilled birth attendance (SBA) } & Basaleem (2012) [30] & SBA usage & $50 \%$ \\
\hline & Choulagai et al. (2013) [16] & SBA usage & $48 \%$ \\
\hline & Dhakal et al. (2011) [18] & SBA usage & $31 \%$ \\
\hline & Mayhew et al. (2008) [20] & SBA usage & $13 \%$ \\
\hline & Kempe et al. (2013) [31] & TBA usage (untrained) & $71(32 \%)$ \\
\hline & & TBA usage (trained) & $10(5 \%)$ \\
\hline & & No one attended delivery & $30(14 \%)$ \\
\hline & & Attended by medical doctor & $37(17 \%)$ \\
\hline & & Attended by nurse-midwife & $29(13 \%)$ \\
\hline \multirow[t]{5}{*}{ Facility-based delivery (FBD) } & Devkota and Bhatta (2011) [17] & Facility-based delivery & $8.5 \%$ \\
\hline & Giacaman et al. (2006) [33] & Facility-based delivery & $96.5 \%$ \\
\hline & & Delivered in govt hospital & $56.4 \%$ \\
\hline & & Delivered in private hospital & $28.3 \%$ \\
\hline & Karkee et al. (2013) [19] & Facility-based delivery & $85 \%$ \\
\hline \multirow[t]{8}{*}{ Postnatal care (PNC) } & Basaleem (2012) [30] & Received any PNC & $20 \%$ \\
\hline & Dhaher et al. (2008) [32] & Received any PNC & $36.6 \%$ \\
\hline & Dhakal et al. (2011) [18] & Received any PNC & $34 \%$ \\
\hline & & Received any within $48 \mathrm{~h}$ of birth & $19 \%$ \\
\hline & & Received from a hospital & $78 \%$ \\
\hline & & Received from a trained physician & $65 \%$ \\
\hline & & Received from a nurse & $20 \%$ \\
\hline & & Received from another health-worker & $16 \%$ \\
\hline \multirow[t]{6}{*}{ Newborn care } & Devkota and Bhatta (2011) [17] & Breastfed within $1 \mathrm{~h}$ of delivery & $7 \%$ \\
\hline & Najem and Al-Deen (2011) [28] & Breastfed within $1 \mathrm{~h}$ of delivery & $7 \%$ \\
\hline & & Never breastfed & $13.5 \%$ \\
\hline & Ulak et al. (2012) [23] & Breastfed within $1 \mathrm{~h}$ of delivery & $57 \%$ \\
\hline & Devkota and Bhatta (2011) [17] & Did not seek health services for newborn complications & $70.4 \%$ \\
\hline & & Did not vaccinate newborn & $35.2 \%$ \\
\hline
\end{tabular}

delivery of key MNH services (e.g. SBA, EmONC, PNC) in Asian and Middle-Eastern FCS. Similarly, recognised demand-side barriers from non-FCS, including lack of awareness, money, and transportation, still need to be sufficiently addressed in Asian and Middle-Eastern FCS. This review revealed evidence gaps in $\mathrm{MNH}$ in Asian and Middle-Eastern FCS, particularly for EmONC, PNC, newborn care, and service usage in acute-conflict situations.

Both low- and middle-income countries were included in this review, and usage of MNH services and their determinants were found to be similar across both categories. These findings reiterate the similarly limited healthcare infrastructure, service delivery and demandside pre-disposing factors, found in FCS irrespective of national income [34, 35]. Most studies focused on remote and marginalised populations within FCS, which while useful in describing in-country social and political fragility, limited generalisability. No studies distilled MNH serviceusage during acute conflict, though Afghanistan, Iraq and the Palestinian Territories included areas of acute conflict. Existing evidence indicates that even better-performing FCS are unable to effectively address $\mathrm{MNH}$ during recurrent crises [6, 36, 37]. Without ensuring EmONC and transportation services during acute crises, maternal and neonatal deaths in FCS will not be curtailed [6]. 
Table 5 Factors affecting maternal and neonatal service usage, ordered by service type and outcome

\begin{tabular}{|c|c|c|c|}
\hline Author (year), country & Outcomes & Determinants & Odds ratio or percentage \\
\hline \multicolumn{4}{|l|}{ Skilled birth attendance } \\
\hline \multirow[t]{10}{*}{ Choulagai et al. (2013) [16], Nepal } & SBA usage & Education & \\
\hline & & $\begin{array}{l}\text { Informally educated } \\
\text { Educated intermediate and above }\end{array}$ & $\begin{array}{l}\text { OR } 1.18(C \mid 0.92-1.51), p<0.05 \\
\text { OR } 4.41(C \mid 2.89-6.72), p<0.05\end{array}$ \\
\hline & & Wealth quintile & \\
\hline & & $\begin{array}{l}\text { Q2 (poorer) } \\
\text { Q5 (wealthiest) }\end{array}$ & $\begin{array}{l}\text { OR } 1.08(\mathrm{Cl} 0.81-1.43), p<0.05 \\
\text { OR } 1.90(\mathrm{Cl} 1.42-2.56), p<0.05\end{array}$ \\
\hline & & Knowledge & \\
\hline & & Knowledge of at least one danger sign & OR $1.31(\mathrm{Cl} 1.08-1.58), p<0.05$ \\
\hline & & Distance & \\
\hline & & Staying $\leq 30 \mathrm{~min}$ from facility & OR $1.31(\mathrm{Cl} 1.08-1.58), p<0.05$ \\
\hline & & ANC use & \\
\hline & & $\geq 4$ ANC visits & OR $2.39(\mathrm{Cl} 1.97-2.89), p<0.05$ \\
\hline \multirow[t]{13}{*}{ Mayhew et al. (2008) [20], Nepal } & SBA usage & Wealth quintile & \\
\hline & & $\begin{array}{l}\text { Q2 (poorer) } \\
\text { Q5 (wealthiest) }\end{array}$ & $\begin{array}{l}\text { OR } 1.6 \text { (Cl 1.2-2.3), } p<0.01 \\
\text { OR } 6.3(\mathrm{Cl} 4.4-8.9), p<0.01\end{array}$ \\
\hline & & Distance & \\
\hline & & $\begin{array}{l}\text { Walking distance to clinic ( } 31-60 \mathrm{~min}) \\
\text { Walking distance to clinic (>90 min) }\end{array}$ & $\begin{array}{l}\text { OR } 0.7(\mathrm{Cl} 0.6-0.8), p<0.01 \\
\text { OR } 0.4(\mathrm{Cl} 0.3-0.6), p<0.01\end{array}$ \\
\hline & & Education & \\
\hline & & Formally educated & OR $3.8(\mathrm{Cl} 3.2-4.5), P<0.05$ \\
\hline & & Earlier been to this health facility & OR $1.7(\mathrm{Cl} 1.3-2.1), p<0.05$ \\
\hline & & At least some basic EmONC equipment in facility & OR $1.0(\mathrm{Cl} 0.7-1.3), p<0.05$ \\
\hline & & $\geq 1$ Community health worker in catchment area & OR $0.7(C l 0.6-0.95), p<0.05$ \\
\hline & & $\geq 1$ female TBA in catchment area & OR $1.3(\mathrm{Cl} 1.0-1.7), p<0.05$ \\
\hline & & $\geq 1$ female doctor or midwife at health facility & OR $1.4(C \mid 1.1-1.8), p<0.05$ \\
\hline & & User fees collected in facility & OR $0.8(C l 0.6-0.96), p<0.05$ \\
\hline & & Antenatal care provided in facility & OR $1.1(\mathrm{Cl} 0.8-1.5), p<0.05$ \\
\hline \multirow[t]{8}{*}{ Siziya et al. (2009) [29], Iraq } & TBA usage & Wealth quintile & \\
\hline & & $\begin{array}{l}\text { Q2 (poorer) } \\
\text { Q4 (wealthier) }\end{array}$ & $\begin{array}{l}\text { OR } 2.90(\mathrm{Cl} 2.49-3.39), p<0.05 \\
\text { OR } 0.79(\mathrm{Cl} 0.65-0.96), p<0.05\end{array}$ \\
\hline & & Age & \\
\hline & & Women aged $25-34$ years & AOR $1.22(\mathrm{Cl} 1.08-1.39), p<0.05$ \\
\hline & & Education & \\
\hline & & Formally educated & OR $1.08(\mathrm{Cl} 0.96-1.22), p<0.05$ \\
\hline & & Children & \\
\hline & & Having 1-2 children & AOR $0.72(\mathrm{Cl} 0.59-0.87), p<0.05$ \\
\hline \multicolumn{4}{|l|}{ Facility-based delivery } \\
\hline \multirow[t]{8}{*}{ Dhakal et al. (2011) [18], Nepal } & $\mathrm{FBD}$ & Age & \\
\hline & & $\begin{array}{l}25+\text { years } \\
20-24 \text { years }\end{array}$ & $\begin{array}{l}\text { OR1.38 (Cl 0.34-5.55), } p<0.001 \\
\text { OR } 2.67(\text { Cl } 0.70-10.19), p<0.001\end{array}$ \\
\hline & & Occupation & \\
\hline & & $\begin{array}{l}\text { Housewife } \\
\text { Working women }\end{array}$ & $\begin{array}{l}\text { OR } 4.77 \text { (Cl 2.16-10.54), } p<0.001 \\
\text { OR } 5.80 \text { (Cl } 0.91-36.84), p<0.001\end{array}$ \\
\hline & & Education & \\
\hline & & $\begin{array}{l}\text { Educated up to primary level } \\
\text { Educated to secondary and above }\end{array}$ & $\begin{array}{l}\text { OR } 2.29 \text { (Cl 0.82-6.37), } p<0.001 \\
\text { OR } 16.59 \text { (Cl 6.27-43.80), } p<0.001\end{array}$ \\
\hline & & ANC use & \\
\hline & & $\geq 1$ ANC visit & OR 20.0 (Cl 2.64-151.51), $p<0.001$ \\
\hline
\end{tabular}


Table 5 Factors affecting maternal and neonatal service usage, ordered by service type and outcome (Continued)

\begin{tabular}{|c|c|c|c|}
\hline \multirow[t]{4}{*}{ Giacaman et al. (2006) [33], Palestine } & \multirow[t]{4}{*}{ FBD } & \multicolumn{2}{|l|}{ Client satisfaction } \\
\hline & & Avoiding public facilities due to dissatisfaction & OR $2.77(\mathrm{Cl} 1.89-4.05), p<0.001$ \\
\hline & & \multicolumn{2}{|l|}{ Financial reasons } \\
\hline & & Insurance or low cost for opting facility & OR $5.83(\mathrm{Cl} 3.96-8.59), p<0.001$ \\
\hline \multirow[t]{6}{*}{ Karkee et al. (2013) [19], Nepal } & \multirow[t]{6}{*}{ FBD } & \multicolumn{2}{|l|}{ Education } \\
\hline & & $\begin{array}{l}\text { Educated up to primary level } \\
\text { Educated to higher-secondary or above }\end{array}$ & $\begin{array}{l}\text { AOR } 3.57 \text { (Cl 1.60-7.94), } p<0.001 \\
\text { AOR } 12.39 \text { (Cl 5.09-30.2), } p<0.001\end{array}$ \\
\hline & & \multicolumn{2}{|l|}{ ANC use } \\
\hline & & $\geq 4$ ANC visits & AOR 2.15 (Cl 1.25-3.69), $p<0.005$ \\
\hline & & \multicolumn{2}{|l|}{ Distance } \\
\hline & & $\begin{array}{l}\leq 30 \min \\
31-60 \min \end{array}$ & $\begin{array}{l}\text { OR } 11.61(C \mid 5.77-24.0), p<0.001 \\
\text { AOR } 1.72(C I 0.93-3.19), p<0.001\end{array}$ \\
\hline \multirow[t]{6}{*}{ Sharma et al. (2014) [21], Nepal } & \multirow[t]{6}{*}{ FBD } & \multicolumn{2}{|l|}{ Education } \\
\hline & & Formally educated & OR $2.8(\mathrm{Cl} 1.58-4.97), p<0.001$ \\
\hline & & \multicolumn{2}{|l|}{ Distance } \\
\hline & & $<60$ min to facility & OR $3.12(\mathrm{Cl} 1.61-0.04), p<0.001$ \\
\hline & & \multicolumn{2}{|l|}{ ANC use } \\
\hline & & Had antenatal visits & OR $5.82(\mathrm{Cl} 2.95-11.5), p<0.001$ \\
\hline \multirow[t]{8}{*}{ Shrestha et al. (2012) [22], Nepal } & \multirow[t]{8}{*}{ FBD } & \multicolumn{2}{|l|}{ Distance } \\
\hline & & Residing in remote area & OR $2.81(\mathrm{Cl} 1.08-7.30), p<0.05$ \\
\hline & & \multicolumn{2}{|l|}{ Community } \\
\hline & & Newer community & OR $2.56(C l 1.19-5.55), p<0.05$ \\
\hline & & \multicolumn{2}{|l|}{ Education } \\
\hline & & Formally educated & OR $2.66(\mathrm{Cl} 1.18-6.01), p<0.05$ \\
\hline & & \multicolumn{2}{|l|}{ ANC use } \\
\hline & & No ANC visits & OR $5.53(\mathrm{Cl} 2.12-14.4), p<0.05$ \\
\hline \multicolumn{4}{|l|}{ Emergency obstetric care } \\
\hline \multirow[t]{6}{*}{ Hirose et al. (2011) [24], Afghanistan } & \multirow[t]{6}{*}{ Delay in seeking EmONC } & \multicolumn{2}{|l|}{ ANC use } \\
\hline & & Lack of ANC & AOR 4.6 (Cl 1.7-12.2), $p<0.05$ \\
\hline & & \multicolumn{2}{|l|}{ Socio-cultural factors } \\
\hline & & $\begin{array}{l}\text { Usage of traditional healer } \\
\text { Weak relationship with her birth family } \\
\text { No plan to use health facility for delivery }\end{array}$ & $\begin{array}{l}\text { AOR } 3.2(\text { Cl 1.2-8.5), } p<0.05 \\
\text { AOR } 2.0(\text { (CI } 0.9-4.4), p<0.05 \\
\text { AOR } 2.0(\text { Cl } 0.9-4.2), P<0.05\end{array}$ \\
\hline & & \multicolumn{2}{|l|}{ System factors } \\
\hline & & Absence of a midwife & AOR $2.2(\mathrm{Cl} 1.1-4.5), p<0.05$ \\
\hline \multirow[t]{8}{*}{ Khorrami et al. (2008) [25], Afghanistan } & \multirow[t]{8}{*}{ Timely EmONC usage } & Distance to facility & \\
\hline & & $\begin{array}{l}<100 \text { miles } \\
\geq 100 \text { miles }\end{array}$ & $\begin{array}{l}N=249(85.3 \%) \\
N=43(14.7 \%)\end{array}$ \\
\hline & & Mode of travel & \\
\hline & & $\begin{array}{l}\text { Automobile } \\
\text { Bus }\end{array}$ & $\begin{array}{l}N=192(65.8 \%) \\
N=97(33.2 \%)\end{array}$ \\
\hline & & Cost as a limitation & \\
\hline & & $\begin{array}{l}\text { Yes } \\
\text { No }\end{array}$ & $\begin{array}{l}N=38(30.7 \%) \\
N=86(69.4 \%)\end{array}$ \\
\hline & & Safety felt about care at this hospital & \\
\hline & & $\begin{array}{l}\text { Moderately safe } \\
\text { Mildly safe }\end{array}$ & $\begin{array}{l}N=100(34.4 \%) \\
N=177(60.8 \%)\end{array}$ \\
\hline
\end{tabular}




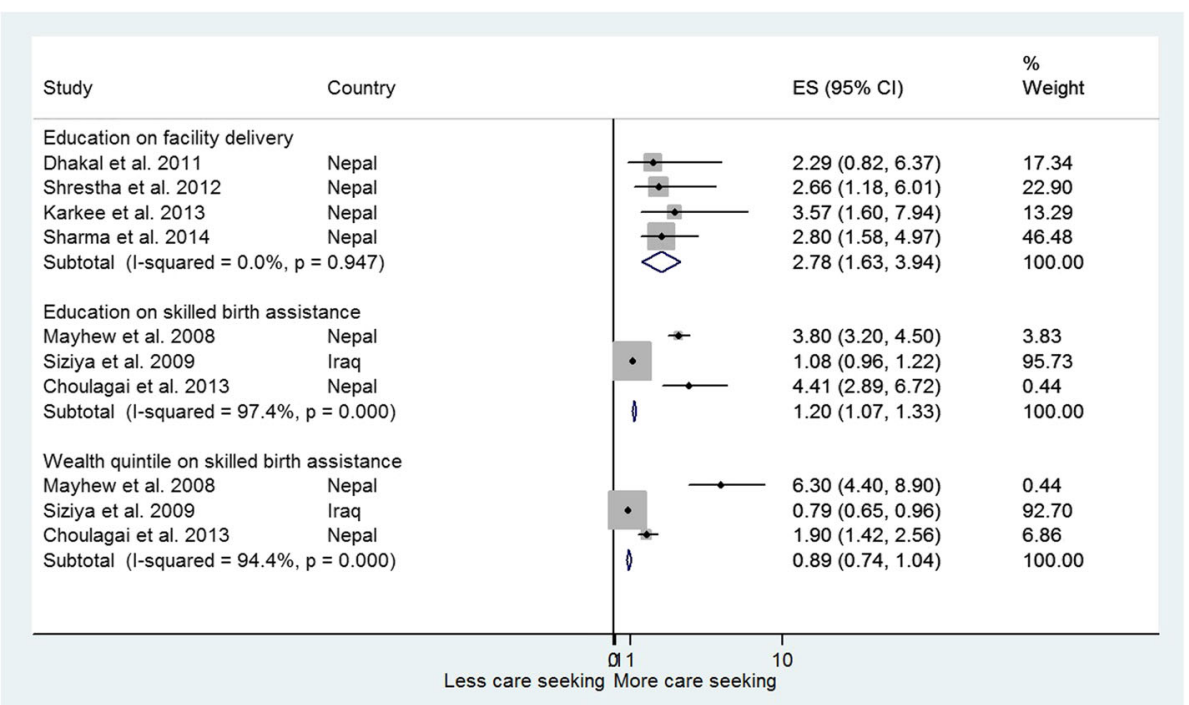

Fig. 2 Association of determinants with MNH care seeking. NB: ES is the estimated statistic (odds ratio); weight, assigned weights by study in the estimation of pooled estimate

Additional research is needed to explore $\mathrm{MNH}$ services access and adaptive responses during acute crises (e.g. EmONC) to improve services sufficiently to achieve global MNH targets [36].

Evidence is particularly limited on usage of some essential maternal and neonatal health services for EmONC, PNC, and newborn care in the FCS of Asia and Middle-East. Overall, MNH service usage trends in Asian and Middle-Eastern FCS were similar to those found for FCS globally (e.g. low SBA and PNC usage) [38-43]. Usage of all MNH services was low, though highest for ANC. However, data collection emphasised receiving any ANC rather than the 4+ ANC visits recommended by WHO. Thus, it is not possible to conclude that existing ANC usage is adequate in these FCS. More research is necessary on timing of first visit and completion of $4+$ ANC visit $[7,20]$.

SBA usage differed significantly across studies within the same countries, though usage was universally low. This intra-country variation appears due to socioeconomic differences, with SBA usage higher in relatively wealthier areas within countries (e.g. Nepal). Additionally, some differences could be attributed to substantial variations on sample sizes across studies. In FCS, presence of a female traditional birth attendant (TBA) or community health worker (CHW) increased the possibility of receiving SBA. As demonstrated by several other resource-constraint settings (e.g. Kenya and Uganda), mainstreaming TBA or CHW into formal primary care system can be a feasible option to improving access to $\mathrm{MNH}$ care in FCS as well $[44,45]$.
Facility-based delivery was higher than SBA usage, and highest in the Palestinian Territories. Literature indicates that the Palestine Territories, despite fragility and ongoing conflict has a comparatively higher rate of dependence on skilled professionals for maternal care, even in refugee camps, though quality of care is a concern [34, 35]. Small geographical size of the territories likely contributes to higher SBA usage [37]. Elsewhere, dependence on TBAs was considerable, and generally attributed to inadequate availability of professional care and potential lack of awareness [31]. Over-reliance on TBAs is commonly reported in FCS globally due to demand- and supply-side barriers to usage of professional services [36, 37].

Usage of newborn services was mixed. Usage of public facilities was higher than for private facilities in these FCS [30], a trend recognised in FCS globally (e.g. Zimbabwe, Somalia) $[7,38,39]$. While findings were mixed on initiation of early breastfeeding within an hour of birth, no study found timely care-seeking for neonatal health concerns. Several women reported using traditional healers instead, as reported in other FCS [7, 38-43].

It is essential to highlight the fundamental inequity found in $\mathrm{MNH}$ services usage in the studies included. Both demand- and supply-side factors favoured wealthier women. For example, MNH services usage was higher among women who were wealthier and in geographically-accessible areas. It is likely these women had more knowledge, income, and/or available services encouraging greater usage. Inequity in $\mathrm{MNH}$ services access is found in both FCS and non-FCS (e.g. Nigeria, Uganda) [41, 42] as social programmes tend to favour 
advantaged populations through existing structures and practices in coverage and implementation [42]. However, FCS must address a relatively stronger vicious circle of inequity due to weak governance and policy paralysis, which augment these inequities [46, 47].

To address the barriers and inequities discussed, FCS require more support than do non-FCS. However, international donor presence does not necessarily streamline health policy-making in FCS $[2,3]$. For example, though targeted policies and strategies for vulnerable groups were planned by donors, often no commensurate improvement in living and health standards is visible, due to issues such as weak aid coordination, planning and institutional support. [2-4] Authors propose adapting targeted policy approaches to improve coordination of aid and planning. Specific demand-side initiatives are needed to address socio-cultural barriers and women's financial access to healthcare in FCS. Given the often limited finances available to women in FCS, policy-level action is necessary to reduce demands for informal payments [26, 31]. Supply-side issues with availability of community-based workers and transportation services were emerging themes that require additional research.

\section{Limitations}

This review is limited by the studies available. Though incorporating a vast literature, this review included only peer-reviewed research articles with a minimum level of methodological quality, thus considerable gaps remain. Authors adhered to the FCS classification used by the World Bank, which may have omitted some potential fragile countries in Asia or the Middle-East. Additionally, authors did not analyse sub-national fragility and therefore omitted non-FCS with higher burdens of maternal and neonatal ill-health (e.g. India) [47]. Caution should be used in interpreting findings, as studies included were primarily non-generalisable.

Despite limitations, this review is relevant for contributing analysis of the evidence on MNH service-usage in FCS and potentially increasing policy attention for this underresearched topic. As this review covers the relatively under-studied factors associated with $\mathrm{MNH}$ and serviceusage in Asian FCS, inclusion of both qualitative and quantitative data strengthened potential triangulation.

\section{Conclusions}

Findings emphasise that poor MNH in FCS is a leading contributor to the burden of maternal and neonatal illhealth in Asia and Middle-East. FCS require additional resources and policy attention if they are to address key barriers to effective $\mathrm{MNH}$ care. While existing evidence is relatively minimal, particularly for acute-crises, similarities in $\mathrm{MNH}$ service-usage and determinants were found in Asian and Middle-Eastern FCS. Overall, usage remains low due to supply-side (e.g. limited services, quality, costs) and demand-side (e.g. education) barriers. More evidence is necessary on timing of first ANC visit, completion of 4+ ANC visits, and increasing usage of EmONC, PNC and newborn services. Initiatives to increase effective coverage of SBA, EmONC, PNC and newborn services are particularly needed, while prevailing service-usage inequities can be tackled through targeted policy approaches.

\section{Abbreviations \\ ANC: Antenatal care; EmONC: Emergency obstetric and newborn care; FCS: Fragile and conflict-affected situations; $\mathrm{MNH}$ : Maternal and neonatal health; PNC: Postnatal care; SBA: Skilled birth attendance}

\section{Acknowledgements}

The authors are grateful to LSHTM for paying to make the paper Open Access.

\section{Funding}

This study did not receive any external funding.

\section{Availability of data and materials}

Not applicable.

\section{Authors' contributions}

SSG, AD and NH conceptualized the review. SSG designed the review protocol, conducted the review and prepared the manuscript. AD contributed to protocol design, review, and manuscript preparation. $\mathrm{NH}$ provided supervision and critically reviewed protocol and manuscript. All authors approved the version for publication.

\section{Competing interests}

Authors declare that they have no competing interests. The views expressed in this paper are those of the authors and do not represent the official views of their organizations.

Consent for publication

Not applicable.

Ethics approval and consent to participate

Not applicable.

\section{Publisher's Note}

Springer Nature remains neutral with regard to jurisdictional claims in published maps and institutional affiliations.

\section{Author details}

'London School of Hygiene and Tropical Medicine (LSHTM), London, UK.

${ }^{2}$ The World Bank, Washington, DC, USA.

Received: 25 September 2015 Accepted: 7 March 2017

Published online: 15 March 2017

\section{References}

1. Bornemisza O, Ranson MK, Poletti TM, Sondorp E. Promoting health equity in conflict-affected fragile states. Soc Sci Med. 2010;70:80-8.

2. Gruber J. Technical assistance for health in non-conflict fragile states: challenges and opportunities. Int J Health Plann Manage. 2009;24:4-20.

3. Witter S. Health financing in fragile and post-conflict states: what do we know and what are the gaps? Soc Sci Med. 2012;75:2370-7.

4. Closing the gap in a generation: Health equity through action on the social determinants of health. Report. Geneva: WHO; 2012.

5. United Nations, "Post-MDG agenda". 2012. http://www.who.int/topics/ millennium_development_goals/post2015/summary_informal_consultation_ memberstates_20121214.pdf. Accessed 25 Aug 2013.

6. Protecting Mothers in Risky Situations. UNFPA 2013. http://www.unfpa.org/ emergencies/motherhood.htm. 2013. Accessed 25 Aug 2013. 
7. Wang $W$, et al. Levels and trends in the use of maternal health services in developing countries. USAID Report 2011. USA.

8. The World Health Organization. 2014. http://www.who.int/mediacentre/ factsheets/fs348/en/. Accessed 12 May 2014.

9. The World Health Organization. 2014. http://apps.who.int/gho/data/view. main.CM1300R?lang=en. Accessed 12 May 2014.

10. The World Health Organization. 2014. http://www.who.int/gho/countries/en/ Accessed 12 May 2014.

11. The World Health Organization. 2014. http://www.childinfo.org/maternal_ mortality.html. Accessed 12 May 2014.

12. Oestergaard MZ, Inoue M, Yoshida S, Mahanani WR, Gore FM, Cousens S, et al. Neonatal mortality levels for 193 countries in 2009 with trends since 1990: a systematic analysis of progress, projections, and priorities. PLoS Med. 2011:8(8):e1001080. doi:10.1371/journal.pmed.1001080.

13. Liberati A, Altman DG, Tetzlaff J, Mulrow C, Gøtzsche PC, loannidis JP, Clarke M, Devereaux PJ, Kleijnen J, Moher D. The PRISMA statement for reporting systematic reviews and meta-analysis of studies that evaluate health care interventions: explanation and elaboration. Ann Intern Med. 2009;151:W65-94.

14. National Institute of Health Research. PROSPERO. International Register of Prospective Systematic Reviews. http://www.crd.york.ac.uk/PROSPERO/. Accessed 27 April 2014.

15. McGill University. Mixed Methods Appraisal Tool (MMAT) - Version 2011. USA. Accessed 1 March 2014.

16. Choulagai, et al. Barriers to using skilled birth attendants' services in mid- and far-western Nepal: a cross-sectional study. BMC Int Health Hum Rights. 2013;13:49. http://www.biomedcentral.com/1472-698X/13/49.

17. Devkota, Bhatta. Newborn care practices of mothers in a rural community in Baitadi, Nepal. Health Prospect. 2011;10:5-9.

18. Dhakal, et al. Skilled care at birth among rural women in Nepal: practice and challenges. J Health Popul Nutr. 2011;29(4):371-8.

19. Karkee, et al. Determinants of facility delivery after implementation of safer mother programme in Nepal: a prospective cohort study. BMC Pregnancy Childbirth. 2013;13:193. http://www.biomedcentral.com/1471-2393/13/193.

20. Mayhew $\mathrm{M}$, et al. Determinants of skilled birth attendant utilization in Afghanistan: a cross-sectional study. Am J Public Health. 2008;98(10):18491856.

21. Sharma, et al. Factors associated with place of delivery in rural Nepal. BMC Public Health. 2014;14:306. http://www.biomedcentral.com/1471-2458/14/306.

22. Shrestha, et al. Changing trends on the place of delivery: why do Nepali women give birth at home? Reprod Health. 2012;9:25. http://www.reproductive-healthjournal.com/content/9/1/25.

23. Ulak, et al. Infant feeding practices in Bhaktapur, Nepal: across-sectional, health facility based survey. Int Breastfeed J. 2012;7:1.

24. Hirose, et al. Difficulties leaving home: a cross-sectional study of delays in seeking emergency obstetric care in Herat, Afghanistan. Soc Sci Med. 2011;73:1003-13.

25. Khorrami, et al. Maternal healthcare needs assessment survey at Rabia Balkhi Hospital in Kabul, Afghanistan. Int J Gynecol Obstet. 2008;101:259-63.

26. Newbrander, et al. Barriers to appropriate care for mothers and infants during the perinatal period in rural Afghanistan: A qualitative assessment. Glob Public Health. doi:10.1080/17441692.2013.827735.

27. Rahmani, Brekke. Antenatal and obstetric care in Afghanistan - a qualitative study among health care receivers and health care providers. BMC Health Serv Res. 2013;13:166. http://www.biomedcentral.com/1472-6963/13/166.

28. Najem, Al-Deen. Breast feeding problems in primipara mothers in early postnatal period. Iraqi J Comm Med. 2011;24(3).

29. Siziya, et al. Socio-economic factors associated with delivery assisted by traditional birth attendants in Iraq, 2000. BMC Int Health Hum Rights. 2009;9:7. doi:10.1186/1472-698X-9-7.

30. Basaleem. Women's reproductive health seeking behavior in four districts in Sana'a, Yemen: quantitative and qualitative analysis. J Community Med Health Educ. 2012;2:5. http://dx.doi.org/10.4172/2161-0711.1000153.

31. Kempe, et al. Yemeni women's perceptions of own authority during childbirth: What does it have to do with achieving the Millennium Development Goals? Midwifery. 2013;29:1182-9.

32. Dhaher, et al. Factors associated with lack of postnatal care among Palestinian women: a cross-sectional study of three clinics in the West Bank. BMC Pregnancy Childbirth. 2008:8:26. doi:10.1186/1471-2393-8-26.

33. Giacaman $\mathrm{R}$, et al. The limitations on choice: Palestinian women's childbirth location, dissatisfaction with the place of birth and determinants. Eur J Public Health. 2007;17(1):86-91.
34. Wick, et al. Childbirth in Palestine. Int J Gynaecol Obstet. 2005;89(2):174-8. doi:10.1016/j.ijgo.2005.01.029.

35. Unicef. Occupied Palestinian territory Mena gender equality profile status of girls and women in the Middle East and North Africa. 2011. Regional office for North Africa and Middle East.

36. World Health Organization. Inter-agency Field Manual on Reproductive Health in Humanitarian Settings. Report. 2010. http://www.who.int/ reproductivehealth/publications/emergencies/field_manual_rh_ humanitarian_settings.pdf. Accessed 15 July 2014.

37. World vision. Guide to maternal, newborn and child health and nutrition in emergencies. 2012. http://www.wvi.org/sites/default/files/ MNCH\%20in\%20Emergencies\%20Guide\%20FINAL_1.pdf. Accessed 15 July 2014.

38. Choguya, et al. Traditional birth attendants and policy ambivalence in Zimbabwe. J Anthropol. 2014:2014:Article ID 750240.

39. The World Health Organization. The African Regional Health Report. 2009.

40. The World Health Organization. More midwives needed to improve maternal and newborn survival. Bull World Health Organ. 2013;91:804-5. http://dx.doi.org/10.2471/BLT.13.021113.

41. Mann, et al. Post-partum mother and child care: a comparison of four African countries. Lancet. 2012;380.

42. Ugboaja, et al. Barriers to postnatal care and exclusive breastfeeding among urbanwomen in southeastern Nigeria. Niger Med J. 2013;54(1):45-50.

43. Stanton C, Hobcraft J, Hill K, Kodjogbe N, Mapeta WT, et al. Every death counts: measurement of maternal mortality via a census. Bull World Health Organ. 2001;79:657-64.

44. Adam MB, Dillmann M, M-k C, Mbugua S, Ndung'u J, et al. Improving maternal and newborn health: effectiveness of a community health worker program in rural Kenya. PLoS ONE. 2014;9(8):e104027. doi:10.1371/journal. pone.0104027.

45. Okuga M, et al. Glob Health Action. 2015;8:23968. http://dx.doi.org/10.3402/ gha.v8.23968

46. Gopalan SS, Mutasa R, Friedman J, Das A. Health sector demand-side financial incentives in low- and middle-income countries: a systematic review on demand- and supply-side effects. Soc Sci Med. 2014;100:72e83.

47. Datta D, Datta PP. Maternal mortality in India: problems and challenges. Asian J Med Res. 2013;2(1):33-5.

48. One world nations online. https://www.britannica.com/place/Middle-East and http://www.duhaime.org/LegalDictionary/M/MiddleEast.aspx. Accessed 27 Apr 2014.

49. The World Bank. 2014. Maternal \& Reproductive Health Services. http:// www.worldbank.org/en/topic/reproductivematernalchildhealth/brief/ reproductive-health-and-the-world-bank-the-facts. Accessed 27 Apr 2014.

50. The World Bank. 2014. Accessed on $1^{\text {st }}$ March 2014. USA. http:// siteresources.worldbank.org/EXTLICUS/Resources/511777-1269623894864/ HarmonizedlistoffragilestatesFY14.pdf. Accessed 27 Apr 2014.

51. Herbert HK, Lee ACC, Chandran A, Rudan I, Baqui AH. Care seeking for neonatal illness in low- and middle-income countries: a systematic review. PLoS Med. 2012;9(3):e1001183. doi:10.1371/journal.pmed.1001183.

\section{Submit your next manuscript to BioMed Central and we will help you at every step:}

- We accept pre-submission inquiries

- Our selector tool helps you to find the most relevant journal

- We provide round the clock customer support

- Convenient online submission

- Thorough peer review

- Inclusion in PubMed and all major indexing services

- Maximum visibility for your research

Submit your manuscript at www.biomedcentral.com/submit 